\title{
Original Article Preliminary Ecological Risk Assessment of 10 PPCPs and their Contributions to the Toxicity of Concentrated Surface Water on an Algal Species in the Middle Basin of Tama River
}

\author{
Hiroyuki Mano, Seiichiro Okamoto \\ Public Works Research Institute, Tsukuba, Japan
}

\begin{abstract}
Investigating the ecological risk of pharmaceuticals and personal care products (PPCPs) using recent data of the occurrence and contributions of PPCPs with potential ecological risks to ecotoxicological effects of chemicals on aquatic organisms in water environments is required. In the present study, preliminary ecological risk assessments of 10 PPCPs were conducted in the middle stream of Tama River and its tributaries using the hazard quotient. An algal growth inhibition test of concentrated river water samples using Pseudokirchneriella subcapitata was also conducted to evaluate the toxicity of each sample and the contributions of PPCPs to toxicity of the water sample to the algal species. The result of preliminary ecological risk assessment showed that the hazard quotients of five PPCPs were over one at some sampling locations. The relatively weak toxicities on P. subcapitata were observed in all the concentrated water samples. The relatively large contribution to relatively weak toxicity of the concentrated water samples on the growth of $P$. subcapitata was found for three of five PPCPs that show potential ecological risks in the middle basin of Tama River.
\end{abstract}

Keywords: bioassay, environmental risk, hazard quotient

\section{INTRODUCTION}

Pharmaceuticals and personal care products (PPCPs) such as fragrances, stimulants, analgesics, antibiotics and hormones have been detected in aquatic environments, and they are recognized as emerging contaminants in environmental science in terms of adverse effects on aquatic organisms $[1,2]$. Most PPCPs could potentially have adverse effects on aquatic ecosystems due to their physiological properties [3]. The occurrence and fate of PPCPs have been reported in Japanese rivers [4-6] and treated wastewater [7,8]. Preliminary risk assessments of several PPCPs have been conducted $[5,9,10]$. As the occurrence of PPCPs can change temporally, ecological risks of PPCPs on aquatic organisms using recent data of the occurrence in Japanese rivers is required.

In addition to the preliminary ecological risk assessment using the hazard quotient (HQ), which is the ratio of predicted environmental concentration (PEC) to predicted no effect concentration (PNEC), investigating effects of PPCPs with potential ecological risks on aquatic organisms in water environments is required. Ecotoxicity tests of a water sample are useful for estimating the ecological risks of chemicals contained in the water sample [11]. The toxicity of a water sample such as river water presents the toxicity of the chemicals contained in the river water sample. It is possible to estimate the contributions of PPCPs to the toxicity of a water sample by comparing the estimated toxicity of individual PPCP with the toxicity of the sample [12]. Investigating the contributions of PPCPs that present high potential ecological risks may provide important information for understanding the ecological risk of the PPCPs in Japanese rivers.

This study conducted initial ecological risk assessments of 10 PPCPs, whose ecological risks are a concern in Japanese rivers, in the middle stream of Tama River and its tributaries. In Tama River, PPCPs have been detected [4,13]. The contribution of each PPCP to the concentrated river-water toxicity to algal growth was estimated by comparing the concentrated water sample toxicity to algal growth with the 
Table 1 Target compounds, CAS number, molecular mass, usage, pKa and $\log K_{\mathrm{ow}}$.

\begin{tabular}{|c|c|c|c|c|c|}
\hline Compound & CAS number & $\begin{array}{l}\text { Molecular mass } \\
(\mathrm{g} / \mathrm{mol})\end{array}$ & Usage & $\mathrm{pKa}$ & $\log K_{o w}{ }^{*}$ \\
\hline Azithromycin & $83905-01-5$ & 748.98 & Antibiotic agent & $8.74^{\text {a) }}$ & 4.02 \\
\hline Bezafibrate & $41859-67-0$ & 361.82 & Lipid lowering drug & $3.6^{\mathrm{b})}$ & 4.25 \\
\hline Caffeine & $58-08-2$ & 194.19 & Psychoactive stimulant drug & $14^{\mathrm{c})}$ & -0.07 \\
\hline Clarithromycin & $81103-11-9$ & 747.95 & Antibiotic agent & $\left.8.99^{a}\right)$ & 3.16 \\
\hline Crotamiton & $483-63-6$ & 203.28 & Antipruritic agent & - & 2.73 \\
\hline Ibuprofen & $15687-27-1$ & 206.28 & Anti-inflammatory drug & $4.41^{\mathrm{d})}$ & 3.97 \\
\hline Ketoprofen & $22071-15-4$ & 254.28 & Anti-inflammatory drug & $4.23^{\mathrm{d})}$ & 3.12 \\
\hline Levofloxacin & $100986-85-4$ & 361.37 & Antibacterial agent & $5.5^{\mathrm{e})}$ & -0.39 \\
\hline Sulfamethoxazole & $723-46-6$ & 253.28 & Sulfonamide antibacterial agent & $\left.1.8-6.0^{f}\right)$ & 0.89 \\
\hline Triclosan & $3380-34-5$ & 289.54 & Antibacterial agent & $8.14^{\mathrm{d})}$ & 4.76 \\
\hline
\end{tabular}

* $\log$ Kow values were derived from EPI Suite ${ }^{\mathrm{TM}}$ ver. 4.11 [34].

a) McFarland et al. [35], b) Beausse [36], c) Nam et al. [37], d) Ozaki et al. [38], e) Yasojima et al. [39], f) Pavlović et al. [40]

toxicity of the PPCP on the basis of the measured concentration and chronic toxicity of PPCP to algal growth. Some reports suggest that algae are more sensitive to some PPCPs than Daphnia and fish species $[14,15]$. Therefore, an algal toxicity test was applied to investigate the toxicities of water samples and the contributions of PPCPs to the toxicity of a water sample were estimated.

\section{MATERIALS AND METHODS}

\section{Target PPCPs}

Ten PPCPs were selected in this study as shown in Table 1. The PPCPs were selected based on an annual report on statistics of production by the pharmaceutical industry in 2010 [16] and previous studies [17,18]. They are mass produced or have been reported to be detected in the water environment in Japan. The 4 of 9 target PPCPs other than triclosan were included in target PPCPs of simultaneous analysis developed by Konishi et al. [19].

\section{Sampling location}

Tama River is a major river in Yamanashi, Kanagawa and Tokyo prefectures in Kanto region, Japan. The river is $138 \mathrm{~km}$ long and covers a catchment area of about $1,240 \mathrm{~km}^{2}$. Effluents from sewage treatment plants are discharged into the river along the middle reaches, in which the effluents comprise up to over $50 \%$ of the river water during low-water season.

The middle basin of Tama River in Tokyo metropolitan area was selected for this study (Fig. 1). Surface water was collected as grab samples at three points in the middle stream of Tama River and four of its tributaries. The location of the sampling sites is shown in Fig. 1 The St. 1 is located upstream of the points where effluents from two sewage treatment plants are discharged. Almost all of the river water at St. c consists of final effluent from a sewage treatment plant. The Sts. 2, 3 and d are located downstream of the points where effluents from sewage treatment plants are discharged. Murata et al. [20] showed that concentrations of some PPCPs in Tama River were higher in winter than in summer due to greater water flow during summer and other factors such as greater photodegradation and biodegradation. Therefore, to conduct a conservative ecological risk assessment of the 10 PPCPs in this study, sampling was performed during the daytime on January 31 and February 16, 2012.

\section{Preparation and analytical methods for PPCPs}

One liter of each sample was collected into two bottles together with EDTA and ascorbic acid, with a concentration at $1 \mathrm{~g} / \mathrm{L}$ to encourage the efficiency of extraction and to prevent oxidation and metal masking, respectively. The samples were immediately transported to the laboratory under cool conditions.

The simultaneous analytical method established by Konishi et al. [19] was adopted for the analysis of target PPCPs other than triclosan with minor modification. One-liter sample was filtered through a glass fiber filter $(\mathrm{GF} / \mathrm{F}$, pore size: $0.7 \mu \mathrm{m}$, Whatman, GE Healthcare, Little Chalfont, UK) and acidified at $\mathrm{pH} 4$ by hydrochloric acid. After the addition of the internal standards (azithromycin- ${ }^{13} \mathrm{C}-\mathrm{d}_{3}$ (TLC PharmaChem, Vaughan, Canada), bezafibrate- $\mathrm{d}_{6}$ (CDN Isotopes, PointeClaire, Canada), caffeine- $\mathrm{d}_{9}$ (CDN Isotopes), clarithromy- 


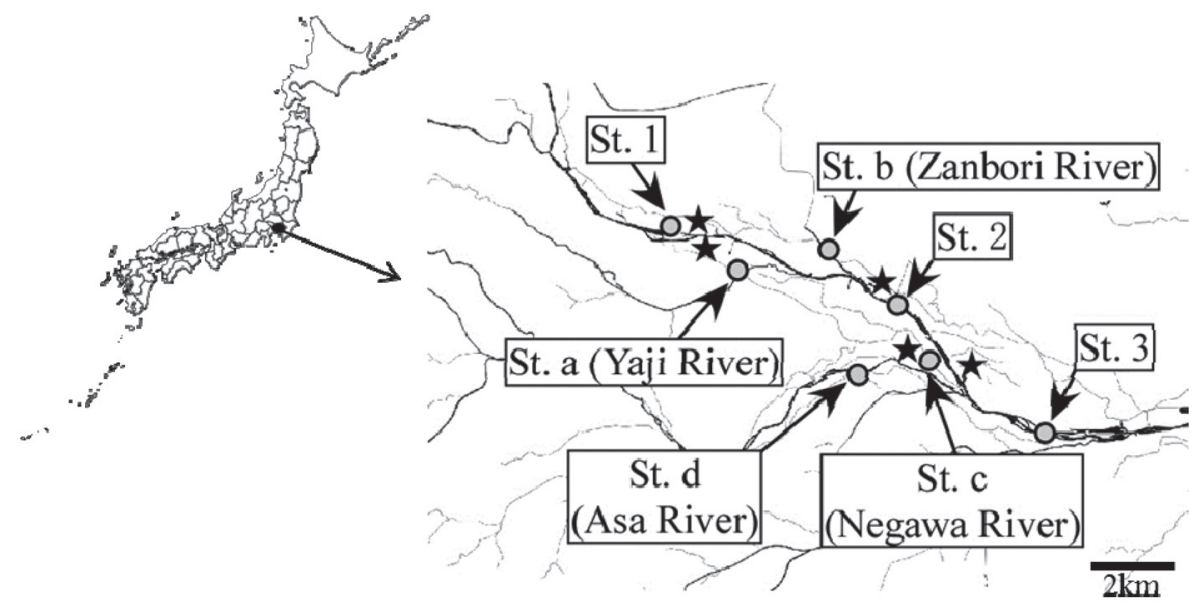

Fig. 1 Sampling location in the middle basin of Tama River. Sts. 1-3 were in the mainstream of Tama River. Sts. a-d were in tributaries. Stars indicate sewage treatment plants.

cin- $-{ }^{13} \mathrm{C}-\mathrm{d}_{3}$ (TLC PharmaChem), crotamiton- $\mathrm{d}_{7}$ (Hayashi Pure Chemical Industries, Osaka, Japan), ibuprofen- $\mathrm{d}_{3}(\mathrm{CDN}$ Isotopes), ketoprofen- $\mathrm{d}_{4}$ (CDN Isotopes), levofloxacin $-{ }^{13} \mathrm{C}-$ $\mathrm{d}_{3}$ (TLC PharmaChem) and sulfamethoxazole- $\mathrm{d}_{4}$ (Tokyo Chemical Industry, Tokyo, Japan)), the filtrate was extracted with an Oasis HLB Plus cartridge (containing $225 \mathrm{mg}$ resin, Waters, Milford, MA, USA) at the rate of $10 \mathrm{~mL} / \mathrm{min}$. Before the extraction, the cartridges were conditioned with both methanol and dilute hydrochloric acid $(\mathrm{pH} 4)$. After the passage of the aliquots, the cartridge was washed by dilute hydrochloric acid, dewatered by centrifugation and purged by nitrogen gas, and then eluted with $6 \mathrm{~mL}$ methanol. The extract was dried under a gentle stream of nitrogen gas and then redissolved in $1 \mathrm{~mL}$ of acetonitrile/ $0.1 \%$ formic acid $(7: 93, v / v)$. After the centrifugation of the extract, supernatant was analyzed by liquid chromatograph (Agilent 1100, Agilent Technology, Santa Clara, CA, USA) equipped with a tandem quadrupole mass spectrometer (API4000, AB Sciex, Framingham, MA, USA) (LC-MS/MS) in both positive-ion (azithromycin, caffeine, clarithromycin, crotamiton, ketoprofen, levofloxacin and sulfamethoxazole) and negative-ion (bezafibrate and ibuprofen) modes. In the positive-ion mode, the analyses were separated with a Hypersil GOLD column $(2.1 \times 100 \mathrm{~mm}, 3 \mu \mathrm{m}$, Thermo Fisher Scientific, Waltham, MA, USA); acetonitrile ( $0.1 \%$ formic acid) and water $(0.1 \%$ formic acid) were used as the mobile phase. In negative-ion mode, a Hypersil GOLD column, acetonitrile and $1 \mathrm{mM}$ aqueous ammonium acetate were used. The $\mathrm{m} / \mathrm{z}$ values of the precursor and product ions monitored for the analysis of target PPCPs are listed in Table 2. The mean recovery rate of a surrogate for each of the nine PPCPs analyzed by LC-MS/ MS from water samples ranged from 34 to 144\% (Table 2).

The method established by Nakada et al. [7] was adopted for the analysis of triclosan with minor modification. A oneliter sample was filtered through a glass fiber filter (GF/B, pore size: $1.0 \mu \mathrm{m}$, Whatman). After $100 \mu \mathrm{L}$ methanol solution containing $1 \mathrm{mg} / \mathrm{L}$ of triclosan ${ }^{13} \mathrm{C}_{12}$ (Cambridge Isotope Laboratories, Tewksbury, MA, USA) was added to the filtrate as a surrogate for triclosan, the filtrate was extracted with an Oasis HLB Plus cartridge (containing $225 \mathrm{mg}$ resin, Waters) at the rate of $10 \mathrm{~mL} / \mathrm{min}$. Prior to the extraction, the Oasis HLB Plus cartridges were conditioned with methanol and MilliQ water. After the passage of the aliquots, the cartridge was washed with MilliQ water, dewatered by centrifugation and purged by nitrogen gas, and then eluted with $10 \mathrm{~mL}$ methanol. The eluent was evaporated just to dryness in a gentle stream of nitrogen gas. The residue was redissolved in $2.5 \mathrm{~mL}$ of hexane/dichloromethane $(75: 25 ; \mathrm{v} / \mathrm{v})$ and then loaded onto a silica gel column (Sep-Pak Si, Waters; $690 \mathrm{mg}$ silica weight) that had previously been washed with $20 \mathrm{~mL}$ of hexane. A further $2.5 \mathrm{~mL}$ of hexane/dichloromethane $(75: 25 ; \mathrm{v} / \mathrm{v})$ was used to elute the sample. The compounds in the column were eluted with $5 \mathrm{~mL}$ of dichloromethane. The dichloromethane fraction in which triclosan was derivatized to acetates with pyridine and acetic anhydride. The acetates were extracted with hexane, evaporated to dryness, and redissolved in a solution of $300 \mu \mathrm{L}$ of isooctane solution containing $100 \mu \mathrm{g} / \mathrm{L}$ of $p$-terphenyl- $\mathrm{d}_{14}$ (Wako Pure Chemical, Osaka, Japan) as the internal standard to account for methodological analyte losses. Triclosan was quantified by 
Table 2 Precursor and product ions for LC-MS/MS analysis of nine PPCPs, monitor ions for the GC-MS analysis of triclosan and mean recovery rate of surrogates from water samples.

\begin{tabular}{|c|c|c|c|c|c|}
\hline \multirow[t]{2}{*}{ Compound } & \multirow[t]{2}{*}{$\begin{array}{l}\text { Precursor ion } \\
(\mathrm{m} / \mathrm{z})\end{array}$} & \multirow[t]{2}{*}{$\begin{array}{l}\text { Product ion } \\
\qquad(\mathrm{m} / \mathrm{z})\end{array}$} & \multirow[t]{2}{*}{$\begin{array}{l}\text { Monitor ion } \\
(\mathrm{m} / \mathrm{z})\end{array}$} & \multicolumn{2}{|c|}{$\begin{array}{l}\text { Recovery rate of a surrogate from } \\
\text { water samples }(\%)\end{array}$} \\
\hline & & & & Mean & SD \\
\hline \multicolumn{6}{|l|}{ LC-MS/MS } \\
\hline Azithromycin & 749.6 & 83.2 & - & 38 & 25 \\
\hline Bezafibrate & 360.1 & 274.1 & - & 34 & 5 \\
\hline Caffeine & 195.1 & 138.1 & - & 144 & 11 \\
\hline Clarithromycin & 748.6 & 158.3 & - & 57 & 19 \\
\hline Crotamiton & 204.2 & 69.1 & - & 116 & 7 \\
\hline Ibuprofen & 205.1 & 161.1 & - & 94 & 7 \\
\hline Ketoprofen & 255.1 & 209.2 & - & 84 & 17 \\
\hline Levofloxacin & 362.2 & 318.2 & - & 76 & 24 \\
\hline Sulfamethoxazole & 254.1 & 156.1 & - & 40 & 17 \\
\hline \multicolumn{6}{|l|}{ GC-MS } \\
\hline Triclosan & - & - & 218,288 & 106 & 9 \\
\hline
\end{tabular}

gas chromatography employing a mass spectrometer (HP 5973 with HP 6890, Agilent Technology) (GC-MS) with an HP-5 MS (Agilent Technology) capillary column after appropriate preparation as fully described by Nakada et al. [7]. The $m / z$ values of the monitor ions for the GC-MS analysis of triclosan are listed in Table 2. The mean recovery rate of the surrogate for triclosan from the water samples was $106 \%$ (Table 2).

The limit of detection of each pharmaceutical was defined as three times the standard deviation of five replicate analyses at the lowest concentration of a standard.

\section{Preparation of samples for algal bioassay}

Detecting the toxicity caused by micropollutants such as PPCPs in a river water sample and estimating values of the toxicity could be facilitated by conducting the algal growth inhibition test of the concentrated river water sample because bioassay in high concentrations of micropollutants could be conducted. In this study, river water samples concentrated by the solid-phase extraction (SPE) method were used for the algal growth inhibition test. Organic compounds were mainly concentrated because PPCPs constitute a group of organic compounds.

One liter of each sample was filtrated using a glass fiber filter (GF/B, Whatman), and then concentrated by the SPE method. The OASIS HLB (Waters) cartridge was washed with methanol and MilliQ water. A filtered water sample was supplied to the cartridge at a flow rate of $10 \mathrm{~mL} / \mathrm{min}$. The compounds retained on the cartridge were eluted with $10 \mathrm{~mL}$ of methanol. The eluent was evaporated just to dryness in a gentle stream of nitrogen. The residue was redissolved in $100 \mu \mathrm{L}$ of dimethyl sulfoxide (DMSO). The SPE sample was preserved at $4^{\circ} \mathrm{C}$ prior to bioassay.

\section{Algal growth inhibition test}

The algal growth inhibition test, in which SPE samples were exposed to a green alga (Pseudokirchneriella subcapitata(NIES-35)) in $72 \mathrm{~h}$, was conducted. The tests were carried out using 96-well microplates according to the method of Yamashita et al. [21]. For exposure of SPE samples, the dilution series was prepared by serial 1:1 dilution with culture medium up to 10 steps. The concentration factors for the SPE samples were 0.1, 0.2, 0.4, 0.8, 1.6, 3.1, $6.3,13,25$ and 50 . The volume of each sample was $240 \mu \mathrm{L}$. The concentration of DMSO in each sample was $0.5 \%$. The solvent control was prepared. Five wells for each of the dilution series and five wells for the solvent control were prepared. After the test, the no observed effect concentration (NOEC) value for each concentrated river sample was estimated. The absorbance $(450 \mathrm{~nm})$ of each well was measured by a microplate reader (ARVO SX-1420, Wallac, Perkin Elmer, Waltham, MA, USA). The cell density was obtained from a calibration curve of absorbance versus cell number to estimate the growth rate. The NOEC value was estimated by comparing the algal cell growth of solvent control and those of treatments with the program EcoTox-Statics Version 2.6d (The Japanese Society of Environmental Toxicology, Japan). The chronic toxicity unit (TU) values of river water samples 
Table 3 Assessment factors for application to toxicity data for estimating PNEC.

\begin{tabular}{lcc}
\hline \hline Toxicity & Number of taxonomic group, in which toxicity data are available & Assessment factor \\
\hline Acute & $1-2$ & 1000 \\
& 3 & 100 \\
\hline Chronic & $1-2$ & 100 \\
& 3 & 10 \\
\hline
\end{tabular}

were calculated from the inverse of NOEC values of river water samples to $P$. subcapitata [22]. A large TU value of a water sample indicates a high adverse effect of the water sample on the growth of P. subcapitata. If the TU value of a water sample is higher than 1, it suggests that chemicals contained in the SPE sample of the water sample can have an adverse effect on the growth of $P$. subcapitata at concentrations equal to the concentrations of the chemicals in the water sample.

\section{Preliminary ecological risk assessment}

Preliminary ecological risk assessments of 10 PPCPs at each sampling location were conducted using the hazard quotient (HQ), which is the ratio of measured environmental concentration (MEC) to PNEC. The maximum measured concentration of each PPCP at each sampling location was used as the MEC of the PPCP at the sampling location. The PNECs of PPCPs for preliminary risk assessments were calculated using published data on the toxicities of three taxonomic groups of algal, crustacean and fish species together with the assessment factors according to the guideline for ecological risk assessment, as directed by the Japan Ministry of the Environment [23]. Toxicity data collected from published data were classified into two types of toxicity, acute toxicity such as EC50 or LC50 for algal growth, mortality or immobilization of crustaceans and fish mortality and chronic toxicity such as NOEC for algal growth, reproduction of crustaceans and fish growth or reproduction. The PNEC values of acute and chronic toxicities were calculated by dividing the minimum values of acute and chronic toxicity values by assessment factors, respectively. The assessment factor was determined by each type of toxicity and the number of taxonomic groups, in which toxicity values are available (Table 3). The lower of the two PNECs was adopted as the PNEC for initial ecological risk assessment in this study. The criteria for ecological risk in the Japan Ministry of the Environment [23] are as follows: A HQ value of less than 0.1 "needs no further survey"; between 0.1 and 1 "needs further survey"; and equal to or higher than 1 "needs detailed evaluation".

\section{Estimation of contributions of PPCPs to the toxicity of river water}

The method by Tamura et al. [12] with minor modification was adopted for estimation of the contributions of PPCPs that were classified into "needs further detailed investigation" by initial ecological risk assessment to the toxicity of concentrated river water to algal growth. The contribution of each pharmaceutical was calculated by the following equation,

$$
\text { Contribution }(\%)=100 \times T U_{\mathrm{PPCP}} / T U_{\text {river water }}
$$

where $\mathrm{TU}_{\mathrm{PPCP}}$ and $\mathrm{TU}_{\text {river water }}$ indicate the chronic toxicity unit of the PPCP and the toxicity of concentrated river water, respectively. The TU of each PPCP was estimated by dividing the measured concentration of the PPCP in river water by the published value of the chronic toxicity (NOEC) of the PPCP to the growth of $P$. subcapitata [24]. If more than one chronic toxicity value of a PPCP to the growth of P. subcapitata is reported, the geometric mean of the chronic toxicity values was calculated for the $\mathrm{TU}_{\mathrm{PPCP}}$. If a single compound is responsible for the concentrated river water toxicity, the TU of the PPCP / TU of the river water ratio becomes unified.

\section{RESULTS AND DISCUSSION}

\section{PPCP concentration}

Table 4 shows the concentrations of 10 PPCPs in water samples at three points in the middle stream of Tama River and four of its tributaries. The median concentrations of the 10 PPCPs in the mainstream were in the following order: crotamiton $(670 \mathrm{ng} / \mathrm{L})>$ clarithromycin $>$ levofloxacin $>$ azithromycin $>$ caffeine $>$ bezafibrate $>$ sulfamethoxazole $>$ triclosan $>$ ibuprofen $=$ ketoprofen $(4 \mathrm{ng} / \mathrm{L})$. The median concentrations of the 10 PPCPs in tributaries were in the following order: caffeine $(355 \mathrm{ng} / \mathrm{L})>$ crotamiton $>$ bezafibrate $>$ clarithromycin $>$ triclosan $>$ sulfamethoxazole $>$ levofloxacin $>$ azithromycin $>$ ibuprofen $>$ ketoprofen $(2 \mathrm{ng} / \mathrm{L})$. The order of median concentrations of 10 PPCPs differed between the mainstream and the tributary in the middle basin of Tama River. The highest concentrations of azithromycin, bezafi- 
Table 4 Concentrations of 10 PPCPs (ng/L) and NOEC values for concentrated river water samples of algal growth inhibition test in 7 sampling locations.

\begin{tabular}{|c|c|c|c|c|c|c|c|c|c|c|c|c|c|c|c|}
\hline & \multirow[b]{3}{*}{ LOD } & \multicolumn{6}{|c|}{ Mainstream } & \multicolumn{8}{|c|}{ Tributary } \\
\hline & & \multicolumn{2}{|c|}{ St. 1} & \multicolumn{2}{|c|}{ St. 2} & \multicolumn{2}{|c|}{ St. 3} & \multicolumn{2}{|c|}{ St. a } & \multicolumn{2}{|c|}{ St. b } & \multicolumn{2}{|c|}{ St. c } & \multicolumn{2}{|c|}{ St. d } \\
\hline & & $\begin{array}{c}\text { Jan. } \\
31\end{array}$ & $\begin{array}{c}\text { Feb. } \\
16\end{array}$ & $\begin{array}{c}\text { Jan. } \\
31\end{array}$ & $\begin{array}{c}\text { Feb. } \\
16\end{array}$ & $\begin{array}{c}\text { Jan. } \\
31\end{array}$ & $\begin{array}{c}\text { Feb. } \\
16\end{array}$ & $\begin{array}{c}\text { Jan. } \\
31\end{array}$ & $\begin{array}{c}\text { Feb. } \\
16\end{array}$ & $\begin{array}{c}\text { Jan. } \\
31\end{array}$ & $\begin{array}{c}\text { Feb. } \\
16\end{array}$ & $\begin{array}{c}\text { Jan. } \\
31\end{array}$ & $\begin{array}{c}\text { Feb. } \\
16\end{array}$ & $\begin{array}{c}\text { Jan. } \\
31\end{array}$ & $\begin{array}{c}\text { Feb. } \\
16\end{array}$ \\
\hline \multicolumn{16}{|l|}{ Compound } \\
\hline Azithromycin & 0.036 & N.D. & N.D. & 150 & 120 & 130 & 120 & 10 & 5.5 & 0.35 & 0.46 & 500 & 430 & 15 & 19 \\
\hline Bezafibrate & 0.04 & 1.2 & 0.63 & 91 & 82 & 72 & 70 & 60 & 140 & N.D. & N.D. & 220 & 120 & 110 & 65 \\
\hline Caffeine & 1.5 & 22 & 25 & 140 & 130 & 150 & 110 & 1600 & 1400 & 52 & 76 & 360 & 240 & 390 & 350 \\
\hline Clarithromycin & 0.42 & 0.82 & 0.93 & 460 & 380 & 340 & 340 & 22 & 20 & 1.8 & 1.4 & 1200 & 900 & 100 & 98 \\
\hline Crotamiton & 0.17 & 12 & 9.0 & 770 & 670 & 710 & 670 & 41 & 58 & 6.0 & 6.4 & 1100 & 1200 & 300 & 240 \\
\hline Ibuprofen & 0.064 & N.D. & N.D. & 6.7 & 3.1 & 3.8 & 3.3 & 9.8 & 8.8 & N.D. & N.D. & 17 & 9.2 & 5.2 & 5.9 \\
\hline Ketoprofen & 0.076 & N.D. & 0.54 & 3.6 & 30 & 2.4 & 18 & 1.1 & 4.3 & 0.17 & 0.64 & 500 & 400 & 0.19 & 1.9 \\
\hline Levofloxacin & 0.71 & N.D. & 0.71 & 180 & 140 & 130 & 130 & 3.6 & 3.4 & 1.3 & 0.86 & 600 & 540 & 28 & 30 \\
\hline $\begin{array}{l}\text { Sulfamethoxa- } \\
\text { zole }\end{array}$ & 0.11 & 0.89 & 0.93 & 72 & 49 & 64 & 56 & 5.9 & 2.3 & 1.3 & 1.4 & 110 & 100 & 35 & 31 \\
\hline Triclosan & 0.1 & 2.20 & 2.0 & 54 & 45 & 46 & 48 & 15 & 14 & 2.9 & 3.9 & 177 & 96 & 27 & 27 \\
\hline \multicolumn{16}{|l|}{ Bioassay } \\
\hline NOEC & & $\geq 50$ & $\geq 50$ & 3.1 & 3.1 & 6.3 & 6.3 & 13 & 13 & $\geq 50$ & $\geq 50$ & 3.1 & 3.1 & 13 & 13 \\
\hline
\end{tabular}

N.D.: Not Detected

LOD: Limit of Detection

brate, clarithromycin, crotamiton, ibuprofen, ketoprofen, levofloxacin, sulfamethoxazole and triclosan were detected in St. c, which is located immediately downstream of a sewage treatment plant (Table 4). In St. c, almost all of the river water consists of effluent from the sewage treatment plant. The inflow of sewage effluent water may contribute to high concentrations of PPCPs in St. c. The highest concentrations of caffeine were observed in St. a. This tributary does not receive sewage effluent water. The inflow of untreated domestic wastewater into the tributary may cause relatively high concentration of caffeine in St. a. In the mainstream of Tama River, concentrations of PPCPs in St. 1, which is located upstream of a sewage treatment plant, were lower than those in Sts. 2 and 3. Concentrations of crotamiton in Sts. 2 and 3 were similar to those reported by Abe and Ishii [13]. High concentrations in Sts. 2 and 3 may be attributed to PPCPs contained in discharged waters and effluents from sewage treatment plants.

In this study, mean recovery rates of azithromycin, bezafibrate and sulfamethoxazole were equal to or less than $40 \%$. Recovery rates of bezafibrate were low in all sampling sites. Compared to other sites, recovery rates of azithromycin and sulfamethoxazole were higher in Sts. 1 and b, in which domestic wastewater and effluents from sewage treatment plants were not discharged into rivers. Mean recovery rates of caffeine and crotamiton were more than $100 \%$. Low recovery rates of azithromycin, bezafibrate and sulfamethoxazole and high recovery rates of caffeine and crotamiton may be affected by interfering substances contained in water samples, physicochemical properties of the PPCPs and the affinity with Oasis HLB. Further study is required to develop the simultaneous analysis.

\section{Preliminary ecological risk assessment}

Preliminary ecological risks for 10 PPCPs were assessed on the basis of the PNEC and MECs in Tama River and its tributaries. Table 5 shows the PNECs of 10 PPCPs and toxicity data to derive the PNECs. The PNECs of 9 PPCPs other than bezafibrate were determined by toxicity values to P. subcapitata. The PNEC of bezafibrate was determined by the toxicity of crustacean, Ceriodaphnia dubia.

The HQ values of 10 PPCPs at each sampling location are shown in Table 6. The HQ values of azithromycin, clarithromycin and triclosan were greater than one in Sts. 2, 3, a, c and d. Our results were similar to those of Komori et al. [5], in which the MEC/PNEC value of clarithromycin was 9.0, indicating the high potential environmental risk of clarithromycin to aquatic organisms in Japanese rivers. The HQ value of levofloxacin exceeded one in Sts. 2, 3 and c. The HQ value of ketoprofen was greater than one in St. c. Results indicate 


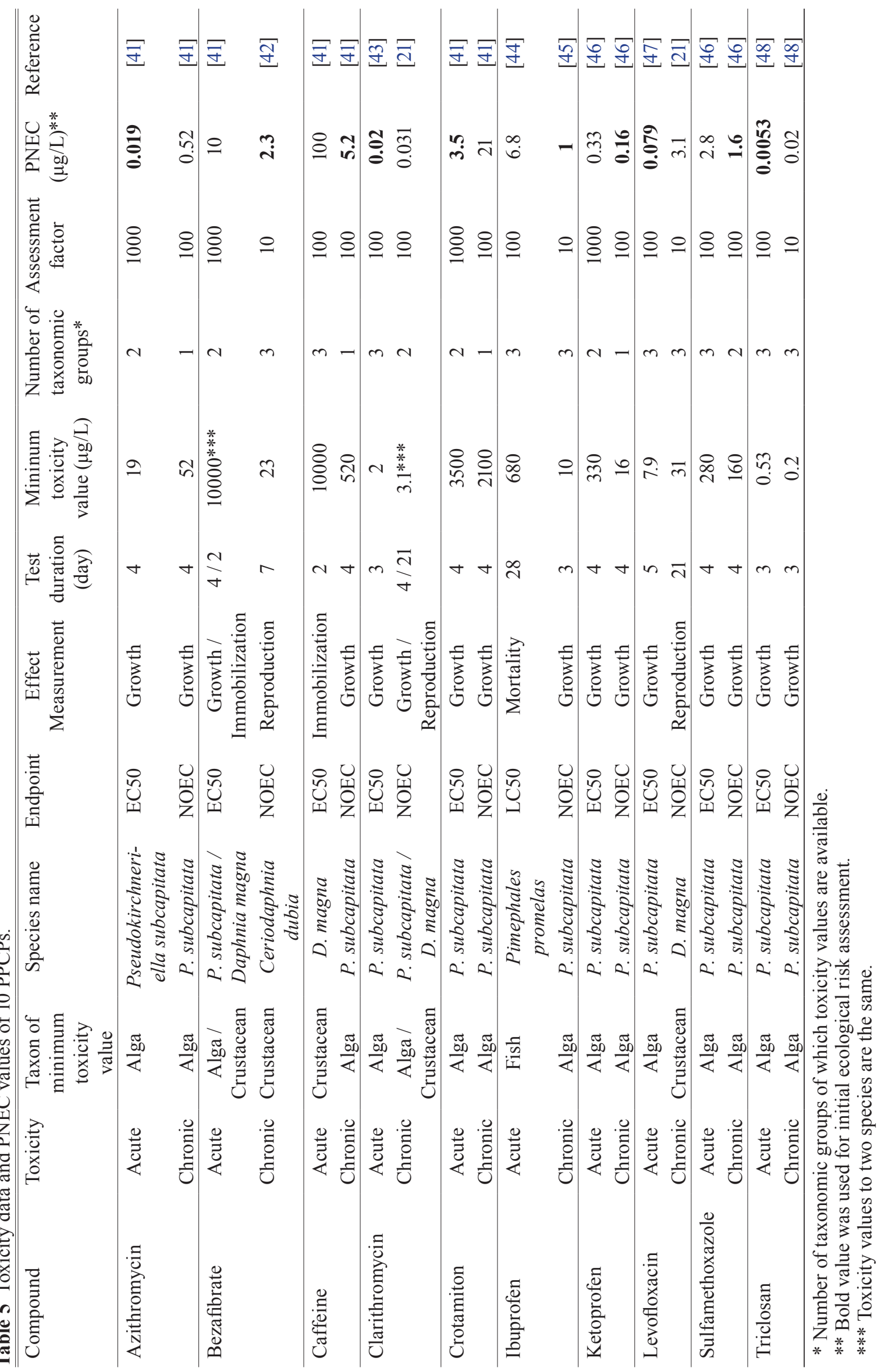


Table 6 Hazard quotient (HQ) values of 10 PPCPs at sampling locations.

\begin{tabular}{|c|c|c|c|c|c|c|c|c|c|c|c|c|c|c|}
\hline \multirow[b]{3}{*}{ Compound } & \multicolumn{6}{|c|}{ Mainstream } & \multicolumn{8}{|c|}{ Tributary } \\
\hline & \multicolumn{2}{|c|}{ St. 1} & \multicolumn{2}{|c|}{ St. 2} & \multicolumn{2}{|c|}{ St. 3} & \multicolumn{2}{|c|}{ St. a } & \multicolumn{2}{|c|}{ St. b } & \multicolumn{2}{|c|}{ St. c } & \multicolumn{2}{|c|}{ St. d } \\
\hline & $\begin{array}{c}\text { Jan. } \\
31\end{array}$ & $\begin{array}{c}\text { Feb. } \\
16\end{array}$ & $\begin{array}{c}\text { Jan. } \\
31\end{array}$ & $\begin{array}{c}\text { Feb. } \\
16\end{array}$ & $\begin{array}{c}\text { Jan. } \\
31\end{array}$ & $\begin{array}{c}\text { Feb. } \\
16\end{array}$ & $\begin{array}{c}\text { Jan. } \\
31\end{array}$ & $\begin{array}{c}\text { Feb. } \\
16\end{array}$ & $\begin{array}{c}\text { Jan. } \\
31\end{array}$ & $\begin{array}{c}\text { Feb. } \\
16\end{array}$ & $\begin{array}{c}\text { Jan. } \\
31\end{array}$ & $\begin{array}{c}\text { Feb. } \\
16\end{array}$ & $\begin{array}{c}\text { Jan. } \\
31\end{array}$ & $\begin{array}{c}\text { Feb. } \\
16\end{array}$ \\
\hline Azithromycin & $-*$ & - & $7.9 * *$ & 6.3 & 6.8 & 6.3 & 0.5 & 0.3 & 0.02 & 0.02 & 26 & 23 & 0.8 & 1.0 \\
\hline Bezafibrate & $<0.01$ & $<0.01$ & 0.04 & 0.04 & 0.03 & 0.03 & 0.03 & 0.06 & - & - & 0.10 & 0.05 & 0.05 & 0.03 \\
\hline Caffeine & $<0.01$ & $<0.01$ & 0.03 & 0.03 & 0.03 & 0.02 & 0.3 & 0.3 & 0.01 & 0.01 & 0.07 & 0.05 & 0.08 & 0.07 \\
\hline Clarithromycin & 0.04 & 0.05 & 23 & 19 & 17 & 17 & 1.1 & 1.0 & 0.1 & 0.1 & 60 & 45 & 5.0 & 4.9 \\
\hline Crotamiton & $<0.01$ & $<0.01$ & 0.22 & 0.19 & 0.20 & 0.19 & 0.01 & 0.02 & $<0.01$ & $<0.01$ & 0.31 & 0.34 & 0.09 & 0.07 \\
\hline Ibuprofen & - & - & $<0.01$ & $<0.01$ & $<0.01$ & $<0.01$ & 0.01 & $<0.01$ & - & - & 0.02 & $<0.01$ & $<0.01$ & $<0.01$ \\
\hline Ketoprofen & - & $<0.01$ & 0.02 & 0.19 & 0.02 & 0.11 & 0.01 & 0.03 & $<0.01$ & $<0.01$ & 3.1 & 2.5 & 0.00 & 0.01 \\
\hline Levofloxacin & - & 0.01 & 2.3 & 1.8 & 1.6 & 1.6 & 0.05 & 0.04 & 0.02 & 0.01 & 7.6 & 6.8 & 0.35 & 0.38 \\
\hline Sulfamethoxazole & $<0.01$ & $<0.01$ & 0.05 & 0.03 & 0.04 & 0.04 & $<0.01$ & $<0.01$ & $<0.01$ & $<0.01$ & 0.07 & 0.06 & 0.02 & 0.02 \\
\hline Triclosan & 0.4 & 0.4 & 10 & 8.5 & 8.7 & 9.0 & 2.8 & 2.6 & 0.5 & 0.7 & 33 & 18 & 5.0 & 5.1 \\
\hline
\end{tabular}

* Hazard quotient was not calculated because the compound was not detected.

** Bold values are greater than one.

that effects of the 5 PPCPs on aquatic organisms and water quality monitoring are necessary for further evaluation in the middle stream of Tama River and its tributaries. High potential ecological risks of azithromycin, clarithromycin and triclosan in rivers outside of Japan have been reported. For example, Valcárcel et al. [25] reported that median HQ values of azithromycin and clarithromycin in Spanish rivers were 27.6 and 5.11, respectively. In addition, Stasinakis et al. [26] reported that the HQ value of triclosan for algae in a Greek river was 70 .

\section{Algal growth inhibition test}

Table 4 shows the NOEC values of concentrated river water samples for algal growth. The chronic TU values of the concentrated river water samples for algal growth are shown in Fig. 2 The chronic TU value differed in sampling locations and ranged from 0.02 to 0.32 . The maximum TU value was observed in Sts. 2 and c. The results indicate that chemicals contained in the SPE sample of the water sample cannot have an adverse effect on the growth of $P$. subcapitata at concentrations equal to the concentrations of the chemicals in the water sample because the TU value of any of the samples was lower than 1.

\section{Contributions of PPCPs to the toxicity of river water}

Table 7 shows the NOEC values of azithromycin, clarithromycin, ketoprofen, levofloxacin and triclosan for the growth of $P$. subcapitata. There was a relatively large difference between two NOEC values of ketoprofen. Ketoprofen is a photolabile chemical, and the photoproducts may be toxic [27]. The differ-

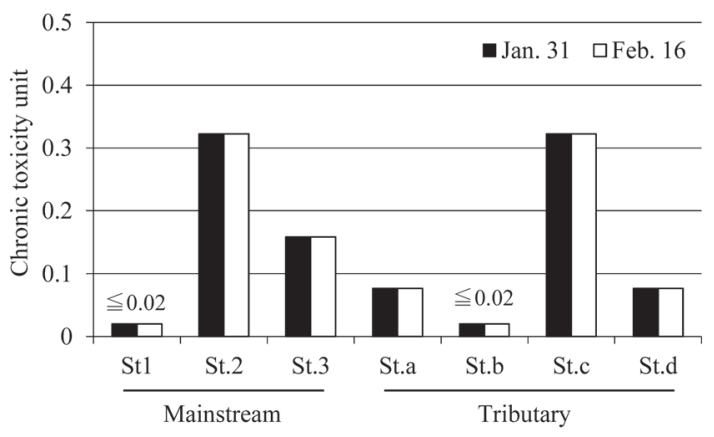

Fig. 2 Results of algal growth inhibition tests of concentrated river water samples. Chronic toxicity unit was derived from the inverse of NOEC value of a river water sample.

ences in test conditions such as the light intensity between the two laboratories might cause the difference between the two NOEC values of ketoprofen. The NOEC value of triclosan was relatively lower in the flask test based on OECD TG 201 than in the microplate test. The NOEC values of the 5 PPCPs were in the following order: triclosan, azithromycin, clarithromycin, ketoprofen and levofloxacin.

The estimated chronic TU values of 5 PPCPs to the growth of P. subcapitata in Sts. 2, 3 and c, in which TU values of concentrated river water were relatively high, were shown in Fig. 3 All estimated TU values of 5 PPCPs were lower than 1. The results indicate that 5 PPCPs in the water sample may have no adverse effect on the growth of $P$. subcapitata at the concentrations of the PPCPs in the water sample.

The contributions of 5 PPCPs to the toxicities of the 
Table 7 NOEC values of 5 PPCPs to the growth of Pseudokirchneriella subcapitata.

\begin{tabular}{lcccc}
\hline \hline Compound & Geometric Mean $(\mu \mathrm{g} / \mathrm{L})$ & Data $(\mu \mathrm{g} / \mathrm{L})$ & Type* & Reference \\
\hline Azithromycin & 7.0 & 4.2 & $\mathrm{M}$ & {$[49]$} \\
& & 5.2 & $\mathrm{M}$ & {$[41]$} \\
& 16 & $\mathrm{M}$ & {$[46]$} \\
\hline Clarithromycin & 10.1 & 3.1 & $\mathrm{M}$ & {$[21]$} \\
& & 5.2 & $\mathrm{M}$ & {$[41]$} \\
& 10 & $\mathrm{M}$ & {$[49]$} \\
& 16 & $\mathrm{M}$ & {$[46]$} \\
& & $<40$ & $\mathrm{~F}$ & {$[47]$} \\
\hline Ketoprofen & 126 & 16 & $\mathrm{M}$ & {$[46]$} \\
& & 1000 & $\mathrm{M}$ & {$[41]$} \\
\hline Levofloxacin & 370 & 260 & $\mathrm{M}$ & {$[41]$} \\
& & 310 & $\mathrm{M}$ & {$[21]$} \\
& & 630 & $\mathrm{M}$ & {$[46]$} \\
\hline Triclosan & 0.2 & $\mathrm{~F}$ & {$[47]$} \\
& 1.3 & 0.5 & $\mathrm{~F}$ & {$[10]$} \\
& & 1 & $\mathrm{~F}$ & {$[50]$} \\
& & 1 & $\mathrm{M}$ & {$[49]$} \\
& 6.3 & $\mathrm{M}$ & {$[46]$} \\
& & $\mathrm{M}$ & {$[41]$} \\
\hline
\end{tabular}

* F and $\mathrm{M}$ indicate algal growth inhibition test using flask and microplate, respectively.

concentrated river water samples to $P$. subcapitata in Sts. 2, 3 and c are shown in Fig. 4 The contributions of azithromycin, clarithromycin and triclosan to the toxicities of the concentrated river water samples were relatively higher than those of ketoprofen and levofloxacin. The contributions of azithromycin, clarithromycin and triclosan in Sts. 2 and 3 on Jan. 31 and Feb. 16 and St. c on Jan. 31 were in the following decreasing order: triclosan, clarithromycin and azithromycin. In St. c on Feb. 16, the contribution of clarithromycin was higher than that of triclosan. The results indicate that PPCPs contained in effluent from sewage treatment plants may contribute to the toxicity of concentrated river water to algal growth.

While river samples in Sts. 2 and c had the highest toxicity value, the contributions of azithromycin, clarithromycin and triclosan in St. c were higher than those in St. 2 at two surveys. In St. 2, other chemicals may contribute to the toxicity of the concentrated river water.

The contributions of azithromycin, clarithromycin and triclosan were equal to or more than $20 \%$ in St. c (Fig. 4). Our results show that in St. c, azithromycin, clarithromycin and triclosan contributed to the toxicity of the concentrated water sample ranging from 20 to $54 \%$ (Fig. 4) and the TU value of the water sample to the growth of $P$. subcapitata was lower than 1 (Fig. 2). The results indicate relatively large contributions of PPCPs to relatively weak toxicity of the concentrated water samples on the growth of P. subcapitata in the middle basin of Tama River.

The toxicity of a river water sample was estimated by conducting an algal growth inhibition test of the SPE sample derived from the river water sample. Some chemicals such as volatile chemicals, metals and inorganic chemicals could not be trapped by the SPE cartridges. These chemicals might attenuate or enhance the toxicity of river water samples. Therefore, the contributions of PPCPs to the toxicities of water samples to the growth of $P$. subcapitata might be overestimated or underestimated in this study. In addition, chemicals such as DOM can interfere with the recovery from the SPE cartridge. Conducting whole effluent toxicity tests of river water samples is required.

If the algal species that live in the middle basin of Tama River are more tolerant to PPCPs than P. subcapitata, no algal species may be harmed in the basin by PPCPs. However, as interspecific and intraspecific variations in the sensitivity to a chemical is frequently observed [28,29], algal species more sensitive to PPCPs than P. subcapitata can inhabit the middle basin of Tama River. For example, blue-green algal species are more sensitive than green algal species to 

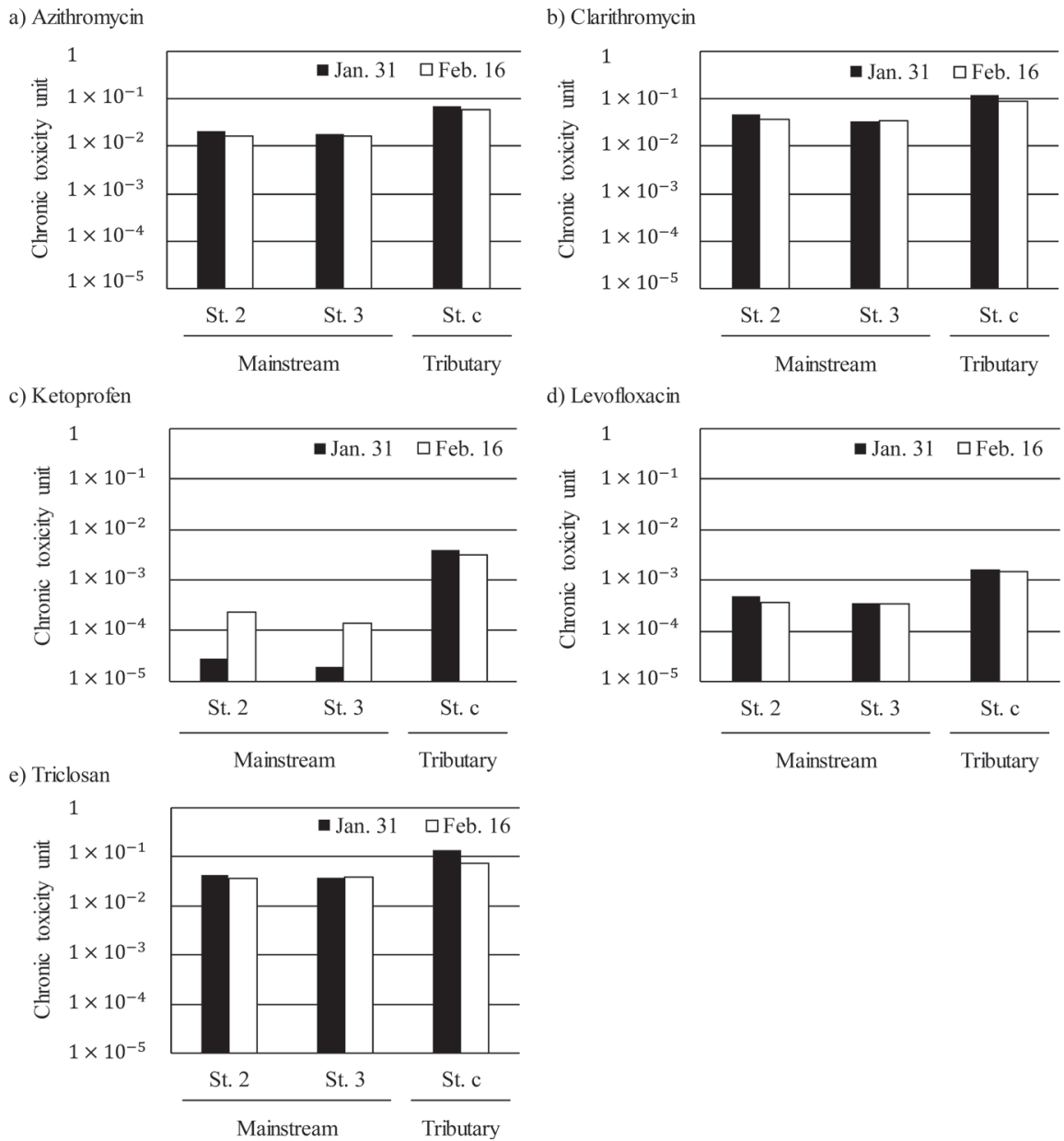

Fig. 3 Estimated chronic toxicity units of 5 PPCPs in Sts. 2, 3 and c. The chronic toxicity unit of a PPCP in a sampling site was calculated by dividing the measured concentration of the PPCP in the sampling site by the published value of the chronic toxicity of the PPCP to the growth of P. subcapitata.

antibiotics [30,31]. Investigating variations in sensitivities to PPCPs among algal species and the effects of PPCPs on the algal community may help us to examine the effects of PPCPs on algal species in the middle basin of Tama River.

In this study, contributions of PPCPs to the toxicities of the concentrated river water samples to the growth of $P$. subcapitata were presented using NOEC values. Values of NOEC are discrete and highly dependent on the statistical analysis and the variance of the control [32]. Further study may be required to investigate the contributions of PPCPs to the toxicities of river water samples to the growth of $P$. subcapitata without use of NOEC values and compare them with results in this study.

\section{CONCLUSIONS}

Preliminary ecological risk assessments of 10 PPCPs in the middle basin of Tama River suggest that azithromycin, clarithromycin, ketoprofen, levofloxacin and triclosan require detailed-level ecological risk assessment. Algal growth inhibition tests of water samples show that there were no adverse effects on an algal species in all water samples. The contributions of 5 PPCPs that had potential ecological risks to the toxicity of each concentrated water sample to an algal species were estimated. Results indicate that the contributions of three PPCPs (azithromycin, clarithromycin and triclosan) were higher than the other selected PPCPs. Relatively large contributions of the PPCPs to relatively low toxicity of the concentrated water samples to the growth of the spe- 
a) Azithromycin

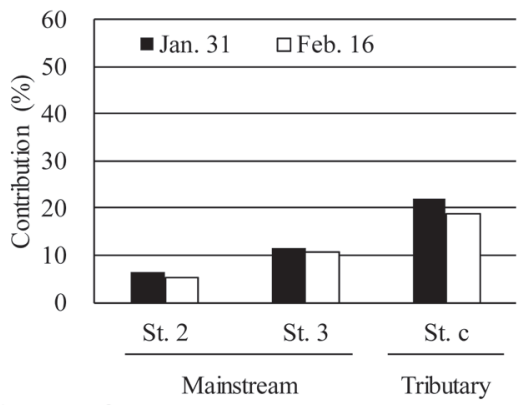

c) Ketoprofen

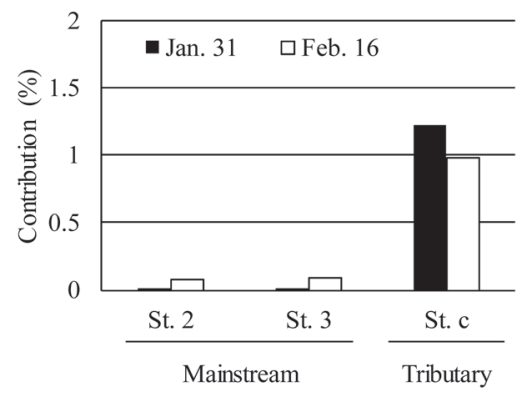

e) Triclosan

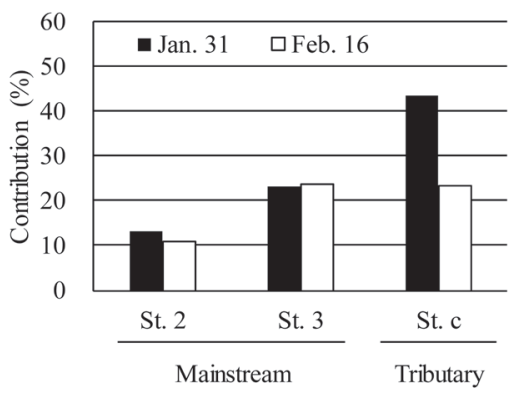

b) Clarithromycin

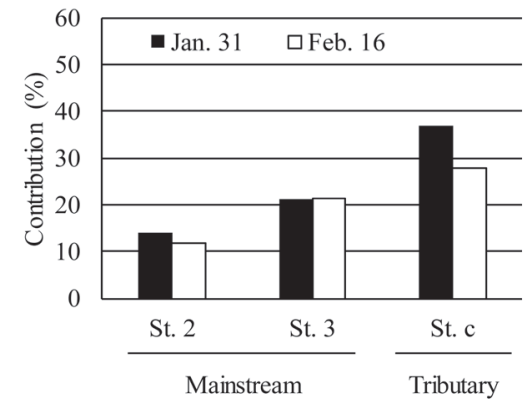

d) Levofloxacin

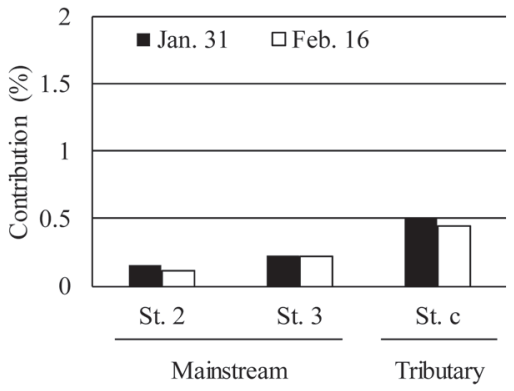

Fig. 4 Contributions of 5 PPCPs to toxicities of concentrated river water samples in St. 2, St. 3 and St. c to the growth of Pseudokirchneriella subcapitata.

cies were found in the middle basin of Tama River. Further studies on variations in sensitivities to PPCPs among algal species and the effects of PPCPs on the algal community are needed to understand the effects of PPCPs on algal species in the middle basin of Tama River. In addition, concentrations of PPCPs in river water and effluents discharged from sewage treatment plants can vary in season and during the day [27,33]. In further studies, seasonal and diurnal variations in the concentrations of PPCPs in river water are required for estimating the ecological risks of PPCPs.

\section{REFERENCES}

[1] Santos LH, Araújo AN, Fachini A, Pena A, DelerueMatos C, Montenegro MC: Ecotoxicological aspects related to the presence of pharmaceuticals in the aquatic environment. J. Hazard. Mater., 175(1-3), 45-95, 2010. [Medline] [CrossRef]

[2] Boxall AB, Rudd MA, Brooks BW, Caldwell DJ, Choi K, Hickmann S, Innes E, Ostapyk K, Staveley JP, Verslycke T, Ankley GT, Beazley KF, Belanger SE, Berninger JP, Carriquiriborde P, Coors A, Deleo PC, Dyer SD, Ericson JF, Gagné F, Giesy JP, Gouin T, Hallstrom L, Karlsson MV, Larsson DG, Lazorchak JM, Mastrocco F, McLaughlin A, McMaster ME, Meyerhoff RD, Moore R, Parrott JL, Snape JR, MurraySmith R, Servos MR, Sibley PK, Straub JO, Szabo ND, 
Topp E, Tetreault GR, Trudeau VL, Van Der Kraak G: Pharmaceuticals and personal care products in the environment: what are the big questions? Environ. Health Perspect., 120(9), 1221-1229, 2012. [Medline] [CrossRef]

[3] Rosi-Marshall EJ, Royer TV: Pharmaceutical compounds and ecosystem function: an emerging research challenge for aquatic ecologists. Ecosystems (N. Y.), 15(6), 867-880, 2012. [CrossRef]

[4] Nakada N, Kiri K, Shinohara H, Harada A, Kuroda K, Takizawa S, Takada H: Evaluation of pharmaceuticals and personal care products as water-soluble molecular markers of sewage. Environ. Sci. Technol., 42(17), 6347-6353, 2008. [Medline] [CrossRef]

[5] Komori K, Suzuki Y, Minamiyama M, Harada A: Occurrence of selected pharmaceuticals in river water in Japan and assessment of their environmental risk. Environ. Monit. Assess., 185(6), 4529-4536, 2013. [Medline] [CrossRef]

[6] Kimura K, Kameda Y, Yamamoto H, Nakada N, Tamura I, Miyazaki M, Masunaga S: Occurrence of preservatives and antimicrobials in Japanese rivers. Chemosphere, 107, 393-399, 2014. [Medline] [CrossRef]

[7] Nakada N, Tanishima T, Shinohara H, Kiri K, Takada $\mathrm{H}$ : Pharmaceutical chemicals and endocrine disrupters in municipal wastewater in Tokyo and their removal during activated sludge treatment. Water Res., 40(17), 3297-3303, 2006. [Medline] [CrossRef]

[8] Matsuo H, Sakamoto H, Arizono K, Shinohara R: Behavior of pharmaceuticals in waste water treatment plant in Japan. Bull. Environ. Contam. Toxicol., 87(1), 31-35, 2011. [Medline] [CrossRef]

[9] Yamamoto H, Nakamura Y, Nakamura Y, Kitani C, Imari T, Sekizawa J, Takao Y, Yamashita N, Hirai N, Oda S, Tatarazako N: Initial ecological risk assessment of eight selected human pharmaceuticals in Japan. Environ. Sci., 14(4), 177-193, 2007. [Medline]

[10] Tamura I, Kagota K, Yasuda Y, Yoneda S, Morita J, Nakada N, Kameda Y, Kimura K, Tatarazako N, Yamamoto H: Ecotoxicity and screening level ecotoxicological risk assessment of five antimicrobial agents: triclosan, triclocarban, resorcinol, phenoxyethanol and p-thymol. J. Appl. Toxicol., 33(11), 1222-1229, 2013. [Medline]

[11] Chapman PM: Whole effluent toxicity testing-usefulness, level of protection, and risk assessment. Environ. Toxicol. Chem., 19(1), 3-13, 2000. [Medline]
[12] Tamura I, Kimura K, Kameda Y, Nakada N, Yamamoto $\mathrm{H}$ : Ecological risk assessment of urban creek sediments contaminated by untreated domestic wastewater: potential contribution of antimicrobials and a musk fragrance. Environ. Technol., 34(12), 1567-1575, 2013. [Medline] [CrossRef]

[13] Abe A, Ishii S: Monitoring of external-use pharmaceuticals in the Tama River basin in Japan and evaluation of removal efficiency of chlorination. J. Jpn. Soc. Water Environ., 33(10), 151-157, 2010 [In Japanese with English abstract]. [CrossRef]

[14] Harada A, Komori K, Nakada N, Kitamura K, Suzuki Y: Biological effects of PPCPs on aquatic lives and evaluation of river waters affected by different wastewater treatment levels. Water Sci. Technol., 58(8), 1541-1546, 2008. [Medline] [CrossRef]

[15] Ginebreda A, Muñoz I, de Alda ML, Brix R, LópezDoval J, Barceló D: Environmental risk assessment of pharmaceuticals in rivers: relationships between hazard indexes and aquatic macroinvertebrate diversity indexes in the Llobregat River (NE Spain). Environ. Int., 36(2), 153-162, 2010. [Medline] [CrossRef]

[16] Ministry of Health, Labour and Welfare: Annual report on statistics of production by pharmaceutical industry in 2010, http://www.mhlw.go.jp/topics/yakuji/2010/ nenpo/index.html, 2011. [In Japanese].

[17] Nakada N, Komori K, Suzuki Y, Konishi C, Houwa I, Tanaka H: Occurrence of 70 pharmaceutical and personal care products in Tone River basin in Japan. Water Sci. Technol., 56(12), 133-140, 2007. [Medline] [CrossRef]

[18] Komori K, Suzuki Y: Occurrence of pharmaceuticals and their environmental risk assessment of urban streams whose basins have different wastewater treatment. J. Jpn. Soc. Water Environ., 32(3), 133-138, 2009 [In Japanese with English abstract]. [CrossRef]

[19] Konishi C, Howa I, Nakada N, Komori K, Suzuki Y, Tanaka H: Development of simultaneous analysis of pharmaceuticals in aqueous samples using LC-MS/ MS. Environ. Eng. Res., 43, 73-82, 2006 [In Japanese with abstract in English].

[20] Murata A, Takada H, Mutoh K, Hosoda H, Harada A, Nakada N: Nationwide monitoring of selected antibiotics: Distribution and sources of sulfonamides, trimethoprim, and macrolides in Japanese rivers. Sci. Total Environ., 409(24), 5305-5312, 2011. [Medline] [CrossRef] 
[21] Yamashita N, Yasojima M, Nakada N, Miyajima K, Komori K, Suzuki Y, Tanaka H: Effects of antibacterial agents, levofloxacin and clarithromycin, on aquatic organisms. Water Sci. Technol., 53(11), 65-72, 2006. [Medline] [CrossRef]

[22] USEPA: Technical support document for water quality-based toxics control, EPA/440/4-85/032. National Technical Information Service, Springfield, VA, 1985.

[23] Ministry of Environment: Environmental risk assessment of chemicals, II. Initial environmental risk assessment of chemicals, http://www.env.go.jp/chemi/ report/h27-01/pdf/chpt1/1-2-1.pdf [accessed in June, 2015] [In Japanese].

[24] SCHER, SCENIHR and SCCS: Toxicity and assessment of chemical mixture, http://ec.europa.eu/health/ scientific_committees/environmental_risks/docs/ scher_o_155.pdf [accessed in January, 2016].

[25] Valcárcel Y, González Alonso S, Rodríguez-Gil JL, Gil A, Catalá M: Detection of pharmaceutically active compounds in the rivers and tap water of the Madrid Region (Spain) and potential ecotoxicological risk. Chemosphere, 84(10), 1336-1348, 2011. [Medline] [CrossRef]

[26] Stasinakis AS, Mermigka S, Samaras VG, Farmaki E, Thomaidis NS: Occurrence of endocrine disrupters and selected pharmaceuticals in Aisonas River (Greece) and environmental risk assessment using hazard indexes. Environ. Sci. Pollut. Res. Int., 19(5), 1574-1583, 2012. [Medline] [CrossRef]

[27] Hanamoto S, Kawakami T, Nakada N, Yamashita N, Tanaka H: Evaluation of the photolysis of pharmaceuticals within a river by 2 year field observations and toxicity changes by sunlight. Environ. Sci. Process. Impacts, 16(12), 2796-2803, 2014. [Medline] [CrossRef]

[28] Marquis O, Miaud C, Ficetola GF, Boscher A, Mouchet F, Guittonneau S, Devaux A: Variation in genotoxic stress tolerance among frog populations exposed to UV and pollutant gradients. Aquat. Toxicol., 95(2), 152-161, 2009. [Medline] [CrossRef]

[29] Nagai T, Taya K, Annoh H, Ishihara S: Application of a fluorometric microplate algal toxicity assay for riverine periphytic algal species. Ecotoxicol. Environ. Saf., 94, 37-44, 2013. [Medline] [CrossRef]

[30] Halling-Sørensen B, Lutzhoft HG, Andersen HR, Ingerslev F: Environmental risk assessment of antibiotics: comparison of mecillinam, trimethoprim and ciprofloxacin. J. Antimicrob. Chemother., 46(Suppl 1): 53-58, 2000. [CrossRef]

[31] González-Pleiter M, Gonzalo S, Rodea-Palomares I, Leganés F, Rosal R, Boltes K, Marco E, FernándezPiñas F: Toxicity of five antibiotics and their mixtures towards photosynthetic aquatic organisms: implications for environmental risk assessment. Water Res., 47(6), 2050-2064, 2013. [Medline] [CrossRef]

[32] van Dam RA, Harford AJ, Warne MS: Time to get off the fence: the need for definitive international guidance on statistical analysis of ecotoxicity data. Integr. Environ. Assess. Manag., 8(2), 242-245, 2012. [Medline] [CrossRef]

[33] Takao Y, Shimazu M, Fukuda M, Ishibashi H, Nagae M, Kohra S, Tabira Y, Ishibashi Y, Arizono K: Seasonal and diurnal fluctuations in the concentrations of pharmaceuticals and personal care products (PPCPs) in residential sewage water. J. Health Sci., 54(2), 240-243, 2008. [CrossRef]

[34] USEPA: EPI Suite, ver. 4.11, http://www.epa.gov/tscascreening-tools/download-epi-suitetm-estimationprogram-interface-v411 [accessed in January, 2016].

[35] McFarland JW, Berger CM, Froshauer SA, Hayashi SF, Hecker SJ, Jaynes BH, Jefson MR, Kamicker BJ, Lipinski CA, Lundy KM, Reese CP, Vu CB: Quantitative structure-activity relationships among macrolide antibacterial agents: in vitro and in vivo potency against Pasteurella multocida. J. Med. Chem., 40(9), 1340-1346, 1997. [Medline] [CrossRef]

[36] Beausse J: Selected drugs in solid matrices: a review of environmental determination, occurrence and properties of principal substances. Trends Analyt. Chem., 23(10-11), 753-761, 2004. [CrossRef]

[37] Nam SW, Choi DJ, Kim SK, Her N, Zoh KD: Adsorption characteristics of selected hydrophilic and hydrophobic micropollutants in water using activated carbon. J. Hazard. Mater., 270, 144-152, 2014. [Medline] [CrossRef]

[38] Ozaki H, Ikejima N, Shimizu Y, Fukami K, Taniguchi S, Takanami R, Giri RR, Matsui S: Rejection of pharmaceuticals and personal care products (PPCPs) and endocrine disrupting chemicals (EDCs) by low pressure reverse osmosis membranes. Water Sci. Technol., 58(1), 73-81, 2008. [Medline] [CrossRef]

[39] Yasojima M, Kobayashi Y, Nakada N, Komori K, Suzuki Y, Tanaka H: Behavior of human antibiotics in wastewater treatment plants. Environ. Eng. Res., 42, 357-368, 2005 [In Japanese with abstract in English]. 
[40] Pavlović DM, Babić S, Horvat AJ, Kaštelan-Macan M: Sample preparation in analysis of pharmaceuticals. Trends Analyt. Chem., 26(11), 1062-1075, 2007. [CrossRef]

[41] Suzuki Y, Komori K, Kitamura K, Kitamura T: A study on behavior of physiological active substances and their adverse effects on ecosystem. In: Public Works Research Institute (ed.): Technical note of PWRI, No. 4157, Public Works Research Institute, Tsukuba, Japan, pp. 131-143, 2009. [In Japanese].

[42] Isidori M, Nardelli A, Pascarella L, Rubino M, Parrella A: Toxic and genotoxic impact of fibrates and their photoproducts on non-target organisms. Environ. Int., 33(5), 635-641, 2007. [Medline] [CrossRef]

[43] Isidori M, Lavorgna M, Nardelli A, Pascarella L, Parrella A: Toxic and genotoxic evaluation of six antibiotics on non-target organisms. Sci. Total Environ., 346(1-3), 87-98, 2005. [Medline] [CrossRef]

[44] Overturf MD, Overturf CL, Baxter D, Hala DN, Constantine L, Venables B, Huggett DB: Early life-stage toxicity of eight pharmaceuticals to the fathead minnow, Pimephales promelas. Arch. Environ. Contam. Toxicol., 62(3), 455-464, 2012. [Medline] [CrossRef]

[45] Brun GL, Bernier M, Losier R, Doe K, Jackman P, Lee HB: Pharmaceutically active compounds in atlantic canadian sewage treatment plant effluents and receiv- ing waters, and potential for environmental effects as measured by acute and chronic aquatic toxicity. Environ. Toxicol. Chem., 25(8), 2163-2176, 2006. [Medline] [CrossRef]

[46] Fukunaga A, Yamashita N, Tanaka H: Evaluation of toxicity of pharmaceuticals based on algal growth inhibition test. Environ. Eng. Res., 43, 57-63, 2006 [In Japanese with English abstract].

[47] Robinson AA, Belden JB, Lydy MJ: Toxicity of fluoroquinolone antibiotics to aquatic organisms. Environ. Toxicol. Chem., 24(2), 423-430, 2005. [Medline] [CrossRef]

[48] Yang LH, Ying GG, Su HC, Stauber JL, Adams MS, Binet MT: Growth-inhibiting effects of 12 antibacterial agents and their mixtures on the freshwater microalga Pseudokirchneriella subcapitata. Environ. Toxicol. Chem., 27(5), 1201-1208, 2008. [Medline] [CrossRef]

[49] Shimizu D, Tanaka H, Yamashita N, Suzuki Y: Algal growth inhibition tests of antibiotics detected in environmental water. 60th annual conference of the Japan society of civil engineers, Tokyo, Japan, 2005. [In Japanese].

[50] Ministry of the Environment: Results of eco-toxicity tests of chemicals conducted by Ministry of the Environment in Japan, https://www.env.go.jp/chemi/ sesaku/02e.pdf [accessed in June, 2015] [In Japanese]. 